\title{
AVALIAÇÃO DO CUSTO DE CONSTRUÇÃO DE UMA ESTRUTURA DE PAVIMENTO EMPREGANDO AGREGADO RECICLADO DE RCD
}

\author{
Evaluation of the costs of construction of a structure paving using recycled \\ aggregate from RCD
}

\author{
Adriana Goulart dos Santos ${ }^{1}$, Ricardo Wiese Teixeira ${ }^{2}$, Eduardo Almeida de Mello ${ }^{3}$, Jaime Teixeira ${ }^{4}$
}

Recebido em 10 de dezembro de 2014; recebido para revisão em 19 de dezembro de 2014; aceito em 01 de abril de 2015; disponível on-line em 07 de julho de 2015.

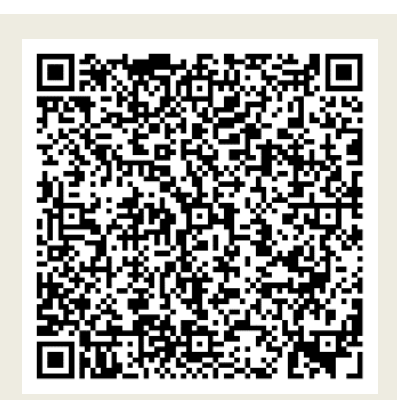

PALAVRAS CHAVE:

Agregado reciclado;

Pavimento;

Dimensionamento de pavimentos;

Resíduos de demolição;

Sustentabilidade.

\section{KEYWORDS:}

Recycled aggregate;

Pavement;

Pavement designer;

Demolition waste;

Sustainability.

\begin{abstract}
RESUMO: O uso de agregados reciclados provenientes de resíduos de construções e demolições (RCD) tem sido vistos como uma alternativa de reduzir a disposição inadequada destes materiais no meio ambiente, como também reduzir os custos de pavimentação. Neste contexto, o presente artigo tem como objetivo dimensionar, para as vias de tráfego intenso da cidade de Joinville-SC, uma estrutura de pavimento usando em sua composição misturas de solo e agregado reciclado e avaliar o seu custo de construção. Para isso, foram realizados ensaios de caracterização física do agregado reciclado e do solo. A partir daí foram dosadas duas misturas com teores diferentes de materiais e avaliado as suas respectivas resistências mecânicas. Com os resultados obtidos constatou-se que as misturas avaliadas podem ser empregadas na construção de camadas de sub-base. Verificou-se que houve uma redução de $8,8 \%$ nos custos de construção de pavimentos usando a mistura de solo-agregado reciclado. Por fim, o estudo apresenta que o uso do agregado reciclado pode ser uma alternativa econômica e tecnicamente viável para a área rodoviária, pois o dimensionamento mostrou que esse material pode ser utilizado para compor as camadas nobres de um pavimento.
\end{abstract}

\begin{abstract}
The use of recycled aggregate from construction and demolition waste has been seen as an alternative to reduce the improper disposal of these materials in the environment, and also reduce the cost of pavements construction. In this context, the present paper aims to pavement designer to the urban roads of the city of Joinville-SC, a structure of pavement that in its composition is used mixtures of soil and recycled aggregate and evaluation it costs of construction. For this, were made physical characterization tests for the recycled aggregate and the soil. Thereafter two mixtures were measured with different levels of materials and analyzed their respective mechanical behaviors. With the results it was verified that mixtures may be employed only in the construction of sub-base layer. It was noted that there was a reduction in the costs of pavements construction using the mixture of soil- recycled aggregate. Finally, the study present that the use of recycled aggregate can be a cost-effective alternative and technically feasible for the road area, because the pavement designer showed that this material can be used to compose the noble layers of a pavement.
\end{abstract}

\footnotetext{
* Contato com os autores:

${ }^{1}$ e-mail : dec2ags@joinville.udesc.br ( A. G. dos Santos )

Professora Adjunta do Departamento de Engenharia Civil - Universidade do Estado de Santa Catarina - UDESC

2 e-mail : ricardo.teixeira@gmail.com ( R. W. Teixeira )

Acadêmico do Curso de Engenharia Civil - Universidade do Estado de Santa Catarina - UDESC

${ }^{3}$ e-mail : eduardoamll@gmail.com ( E. A. Mello)

Acadêmico do Curso de Engenharia Civil - Universidade do Estado de Santa Catarina - UDESC.

${ }^{4}$ e-mail : jaimeejt@gmail.com ( J. Teixeira )

Acadêmico do Curso de Engenharia Civil - Universidade do Estado de Santa Catarina - UDESC.
} 


\section{INTRODUÇÃO}

O crescente processo de urbanização tem contribuído para o desenvolvimento da indústria da construção civil no Brasil e no mundo. O setor da construção civil é responsável pela intensa extração de recursos naturais e geração de resíduos sólidos. $O$ volume de resíduos da construção e demolição (RCD) tem afetado a qualidade de vida principalmente nas cidades de médio e grande porte em diversos países. Para se ter uma ideia, de acordo com Motta et al. (2005), a geração média per capita de resíduos de concreto na Coréia do Sul é de $520 \mathrm{~kg} /$ (pessoa.ano); na Itália, a magnitude é cerca de $600 \mathrm{~kg} /$ (pessoa.ano); na Holanda, um dos maiores índices da Europa, a taxa média atinge a marca de $1.000 \mathrm{~kg} /$ (pessoa.ano); e no Brasil, em algumas cidades tem-se registrado em média 500 $\mathrm{kg}$ de resíduo/(pessoa.ano). A disposição inadequada desses resíduos causa inúmeros problemas sócios ambientais, tais como: a ocupação irregular de áreas urbanas, o exaurimento da capacidade de armazenamento de aterros sanitários, o assoreamento de córregos e rios, o entupimento de redes de drenagem, a proliferação de vetores de doenças e degradação da paisagem urbana e rural. No Brasil a elevada quantidade de RCD, que representa mais de $50 \%$ da massa de resíduos sólidos urbanos (Marinho e Silva, 2012), preocupa quando se trata de disposição final. É um material que ocupa um grande espaço nos aterros, e muitas vezes, é descartado sem cuidado nenhum, ocasionando problemas na saúde pública, no meio ambiente e consequentemente nos cofres públicos.

Em função disto, muitos pesquisadores em todo o mundo vêm tentando encontrar alternativas para que os problemas decorrentes deste processo sejam minimizados, ou até mesmo sanados, visando à sustentabilidade do setor construtivo. Apesar de causarem tantos problemas, os resíduos sólidos da construção civil, especificamente os compostos por concretos, argamassas e elementos cerâmicos, devem ser vistos como fonte de materiais alternativos de grande potencial e utilidade na engenharia.
De acordo com Oliveira et al. (2011), em várias cidades brasileiras já existem usinas de reciclagem de RCD instaladas. Os investimentos para a montagem e manutenção desse tipo de usina, parece ter resultado positivo, principalmente para o setor público. Dados da usina de reciclagem Estoril, instalada e mantida pela Prefeitura Municipal de Belo Horizonte - MG mostram que o valor investido foi amortizado já nos primeiros sete meses de funcionamento, considerando apenas a eliminação da limpeza urbana do RCD e a substituição de agregados naturais pelos reciclados. Oliveira et al. (2011) citou um estudo realizado em Fortaleza, no qual foi estimado uma economia de R\$ 435 mil por ano substituindo agregados naturais da usina de asfalto da Prefeitura Municipal de Fortaleza pelos agregados reciclados da usina de reciclagem de RCD privada existente no município. Esse estudo foi realizado no ano de 2009. Segundo Melo; Ferreira e Costa (2013) esse agregado reciclado é usado pelo setor público em obras de pavimentação. Nesse caso, os requisitos técnicos para empregabilidade independem do controle de qualidade rigoroso.

Estudos realizados em vários países, inclusive no Brasil, demonstraram que o uso do resíduo sólido da construção e demolição em camadas da pavimentação é uma alternativa interessante (Hortegal, Ferreira e Sant'ana, 2009). Segundo Motta (2005), em alguns países a pavimentação com agregados reciclados já é usada em grande escala. No Brasil as primeiras experiências com agregados reciclados em camadas de pavimentação ocorreram na década de 80.

Triches e Kryckyj (1999) pesquisaram agregados reciclados de Florianópolis-SC misturados com solo areno-siltoso e argiloso. Realizaram ensaios de peneiramento, para obter a granulometria do material, de compactação e California Bearing Ratio - CBR. Os resultados da pesquisa apresentaram que o material pode ser usado em camadas de reforço do subleito e subbase, além de possuir potencial para ser empregado na redução da plasticidade do solo de fundação. 
Para Carneiro et al. (2001) o aproveitamento do agregado reciclado de RCD em pavimentação apresenta muitas vantagens, tais como: utilização de quantidade significativa de material reciclado, tanto na fração miúda quanto na graúda; simplicidade dos processos de execução do pavimento e de produção do agregado reciclado (separação e britagem primária), sem contar com a preservação das jazidas naturais e a redução nos custos das obras. Todos estes aspectos contribuem para a difusão desta forma de reciclagem e a possibilidade de uso dos diversos materiais componentes do resíduo (concretos, argamassas, materiais cerâmicos, areia, pedras, etc.). Os resíduos da construção e demolição por serem materiais nobres do ponto de vista da engenharia, apresentam por meio de ensaios laboratoriais resistência e baixa expansão, tais características mostram o seu grande potencial de reciclagem como agregado para pavimentação (LEITE, 2007).

Silva, Silva e Barroso (2008) estudaram a mistura de dois tipos de agregados reciclados de RCD puro (um graúdo e outro miúdo) e um tipo de solo, todos os materiais oriundos da Região Metropolitana de Fortaleza, para aplicar na área de pavimentação nesta mesma região. Foram feitos ensaios, no primeiro momento, apenas com o solo, e com os resultados obtidos, não se mostrou adequado para o uso em pavimentação, pois os seus limites de consistência (Limite de Liquidez e Limite de Plasticidade) eram elevados e o valor de CBR era inferior ao mínimo necessário para que o material possa ser utilizado em camadas da pavimentação. Quando ensaiada a mistura dos três materiais mostrou-se viável tecnicamente para o uso em camadas de base e sub-base dos pavimentos de pequeno volume de tráfego.

No contexto da pavimentação, dados da Confederação Nacional do Transporte (CNT), do ano de 2013, mostram que no Brasil ainda existem muitas rodovias sem pavimentação. Em abril do mesmo ano, foi verificado que dos 1.713 .885 quilômetros de rodovias existentes, somente $11,8 \%$ (202.589 quilômetros) são pavimentados, ou seja, 1.511.296 quilômetros não possuem pavimentação. Entre os anos de 2004 e 2013, a extensão da malha rodoviária federal pavimentada cresceu apenas 12,1\%, passando de, aproximadamente, $57,9 \mathrm{mil} \mathrm{km}$ para pouco mais de $64,9 \mathrm{mil} \mathrm{km}$. Ainda de acordo com o CNT (2013), o modesto crescimento observado evidencia que a disponibilidade de infraestrutura rodoviária, no Brasil, ainda é reduzida, comparativamente a países de grandes dimensões (Rússia, Estados Unidos, China, Canadá e Austrália). A densidade da malha rodoviária pavimentada do Brasil, obtida pela divisão da quilometragem de rodovias existentes pela área territorial do país, é a menor entre esses países: $23,8 \mathrm{~km}$ de infraestrutura para cada 1.000 $\mathrm{km}^{2}$ de área.

Além da reduzida extensão da malha rodoviária, existem graves problemas associados à conservação das vias pavimentadas existentes. A má qualidade das rodovias, aliada à ausência de serviços de manutenção, implica custos elevados para os usuários, e, também, maiores gastos com a restauração dos pavimentos, requerendo soluções técnicas mais robustas e onerosas para a reversão desse cenário.

Dada a importância do transporte rodoviário na movimentação de bens e pessoas no Brasil, são necessários investimentos contínuos visando à manutenção, recuperação e a ampliação da malha viária pavimentada brasileira, principalmente nos trechos mais críticos. O presente trabalho visa dar uma contribuição ao estudo de materiais alternativos para a construção de camadas estruturais de pavimentos a fim de propiciar a redução dos custos de construção, bem como assegurar a sustentabilidade desse setor construtivo.

\section{OBJETIVO}

O objetivo principal deste trabalho foi dimensionar, para vias de tráfego intenso da cidade de Joinville-SC, uma estrutura de pavimento usando em sua composição misturas de solo e agregado reciclado proveniente de RCD e 
verificar qual é redução nos custos de construção desse tipo de pavimento quando comparado àquela estrutura de pavimento usualmente implantada na cidade.

\section{METODOLOGIA}

Para o desenvolvimento do trabalho, primeiramente, foram coletados o solo e o agregado reciclado de $\mathrm{RCD}$. O agregado reciclado foi fornecido por uma usina de reciclagem de resíduos de construções e demolições com sede na cidade de Joinville-SC, enquanto que o solo foi coletado em jazida no mesmo município. A coleta dos agregados foi realizada de acordo com a norma DNER PRO 120 (1997). Após a coleta, o material foi transportado em sacos de, aproximadamente, 40 kg ao Laboratório de Estradas do CCT/UDESC, onde foram realizados todos os ensaios.

Para a determinação da localização da jazida foi utilizada a ferramenta Google Earth. Localizou-se uma jazida próxima à região urbana de Joinville - SC. As coordenadas geográficas de localização da jazida são: $26^{\circ} 13^{\prime} 47,32^{\prime \prime}$ S e $48^{\circ} 51^{\prime}$ 41,54" O, como mostra a Figura 1. Essa localização foi escolhida pela facilidade de acesso. A Figura 1 também mostra o aspecto visual da jazida. A Figura 2 mostra o aspecto visual do agregado reciclado.

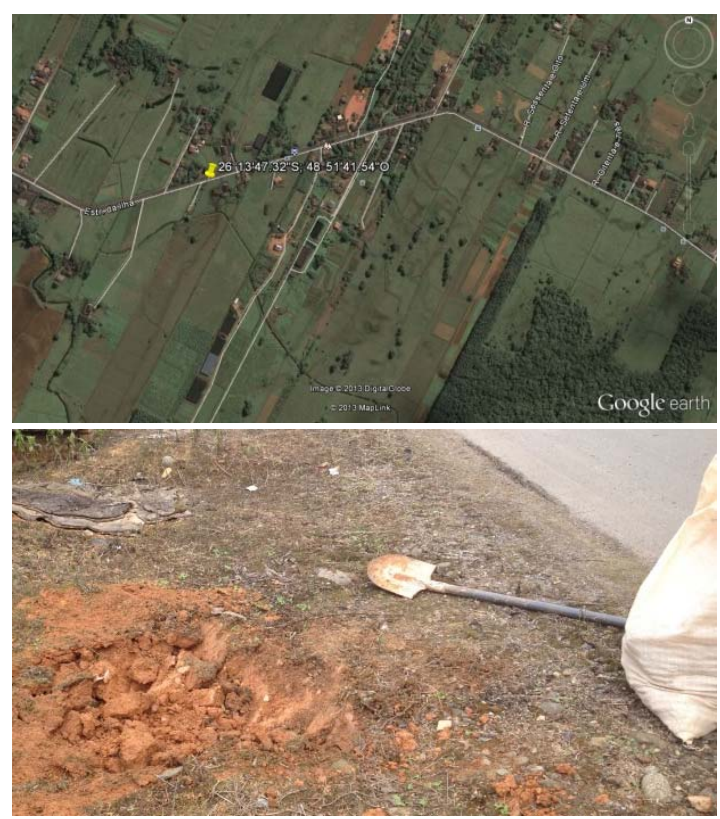

FIGURA 1: Localização da jazida do solo e o seu aspecto visual.

FONTE: Google Earth (2013).

Do ensaio de compactação, na energia intermediária, a umidade ótima do material é de

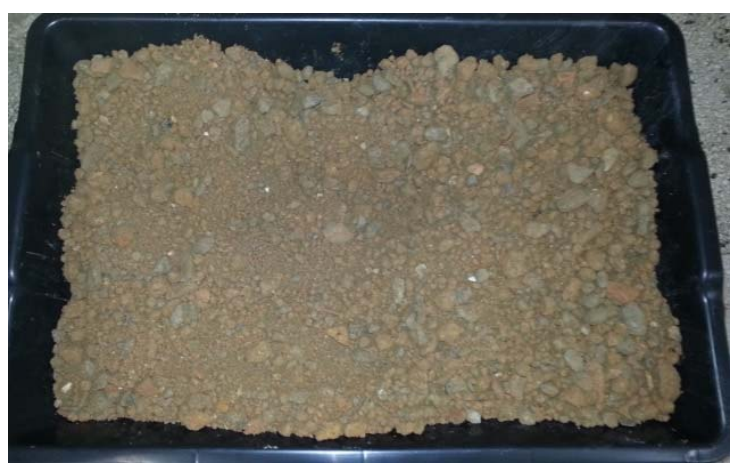

FIGURA 2: Aspecto visual do agregado reciclado de RCD.

A partir disso, o agregado reciclado e o agregado natural (solo) tiveram suas propriedades físicas e de resistência mecânicas ensaiadas separadamente. Após a obtenção dessas informações é que se procederam a dosagem da mistura de solo-agregado reciclado e os ensaios necessários para avaliação de sua resistência mecânica.

\subsection{CARACTERIZAÇÃO FÍSICA DOS MATERIAIS}

\subsubsection{Solo}

O solo foi caracterizado quanto aos limites de consistência através da execução dos ensaios de limite de liquidez, segundo a NBR 6459 (ABNT, 1984) e limite de plasticidade, segundo a NBR 7180 (ABNT, 1984), sendo determinado também $o$ índice de plasticidade. A análise granulométrica do solo foi realizada de acordo com a NBR 7181 (ABNT, 1984), bem como a determinação de sua densidade real.

De acordo com a NBR 7182 (ABNT, 1987) executaram-se os ensaios de compactação com uso do compactador mecânico, para obtenção da umidade ótima e massa específica seca máxima. Quanto à resistência mecânica, o solo foi avaliado pelo ensaio de Índice de Suporte Califórnia (CBR), o qual é preconizado pela NBR 9895 (ABNT, 1987).

Em relação ao solo trata-se de um solo do tipo argiloso. Segundo a classificação HRB (Highway Research Board) é um solo A-7-5. A massa específica dos grãos é de $1,61 \mathrm{~g} / \mathrm{cm}^{3}$, o limite de liquidez é de 53,3\%, o limite de plasticidade é de $40,97 \%$ e o coeficiente de uniformidade igual a 55 .

de materiais indesejáveis, absorção, forma dos grãos e distribuição granulométrica. A Tabela 1 
$26,2 \%$ e a massa especifica aparente seca de 1,534 $\mathrm{g} / \mathrm{cm}^{3}$. O Índice de Suporte Califórnia do solo, na umidade ótima, apresentou um valor igual a 9,37\%.

De acordo com os resultados do solo natural pode-se observar que o material não se mostrou adequado para o uso em pavimentação, segundo as normas vigentes no país, uma vez que seus limites de consistência são muito elevados e o valor de CBR é inferior ao mínimo necessário para que o material possa ser utilizado na área rodoviária.

Ressalte-se que para o solo ser usado em pavimentação, o DNIT (Departamento Nacional de Infraestrutura Terrestre) limita o CBR, para energia de compactação intermediária, no mínimo igual a $20 \%$ para sub-base e $60 \%$ para base; expansão no máximo de $1 \%$ para sub-base e $0,5 \%$ para base; índice de grupo (IG) igual a zero; limite de liquidez (LL) no máximo $25 \%$ e índice de plasticidade (IP) no máximo $6 \%$.

\subsubsection{Agregado reciclado}

As características físicas do agregado reciclado foram determinadas a partir dos seguintes ensaios: composição dos agregados, teor apresenta algumas características físicas mínimas, de acordo com a NBR 15115 (ABNT, 2004), que o agregado reciclado deve apresentar para poder ser utilizado na construção de camadas de pavimentos.

Com o processo de separação e classificação visual pode-se verificar que o agregado reciclado analisado era composto de frações cimentícias (argamassas e concreto), rochosas (britas), cerâmica (pisos e azulejos), resíduos indesejáveis (papel, madeira, plástico, etc) e material fino (grãos que passaram na peneira $4,8 \mathrm{~mm})$. Após a separação por classes, determinouse a porcentagem em massa de cada material constituinte do material reciclado, em relação à fração retida na peneira $4,8 \mathrm{~mm}$, desconsiderando a parcela fina. Pelos valores obtidos foi possível constatar que a maior concentração é de materiais cimentícios (41,69\%), seguida de materiais rochosos (53,68\%). Segundo a NBR 15115 (ABNT, 2004) o agregado reciclado é denominado de cimentício quando possui na sua fração graúda mais de $90 \%$ em massa de fragmentos à base de materiais cimentícios e rochas. Logo, considera-se que o agregado analisado é do tipo cimentício.

\begin{tabular}{|c|c|}
\hline Características físicas & Recomendações NBR 15115 \\
\hline $\begin{array}{l}\text { Dimensão Máxima } \\
\text { Característica (mm) }\end{array}$ & 63,5 \\
\hline $\begin{array}{c}\text { Passante na peneira } \\
0,42 \mathrm{~mm}(\%)\end{array}$ & Entre 10 e 40 \\
\hline $\begin{array}{l}\text { Coeficiente de } \\
\text { Uniformidade }\end{array}$ & $\geq 10$ \\
\hline CBR (\%) & $\geq 60$ (p/base) e $\geq 20$ (p/sub-base) \\
\hline Expansão & $\geq 0,5$ (p/base) e $\geq 1,0$ (p/sub-base) \\
\hline
\end{tabular}

O teor de absorção encontrado nesta pesquisa foi de $15,8 \%$. No tocante à forma dos grãos verificou-se que há predominância da forma diz respeito à porcentagem de material passante na peneira $0,42 \mathrm{~mm}$, cujo valor foi de $25 \%$. Pela NBR 15115 (ABNT, 2004) este valor deve estar 
cúbica na amostra analisada, cujo valor é de 65,7\%. A forma lamelar apresentou cerca de $1 / 4$ do total das partículas analisadas estando de acordo com a NBR 15115 (ABNT, 2004), que recomenda que a porcentagem máxima para grãos nesse formato seja de $30 \%$.

Do ensaio de granulometria obteve-se a seguinte composição do material: $40 \%$ de pedregulho, $22,21 \%$ de areia grossa, $13,82 \%$ de areia média, $14,38 \%$ de areia fina e $9,88 \%$ de finos. De acordo com a NBR 15115 (ABNT, 2004) o coeficiente de uniformidade $(\mathrm{Cu})$ do agregado deve apresentar valor maior ou igual a 10. Nesta pesquisa foi encontrado um valor igual a 64, o que indica que o agregado reciclado ensaiado é bem graduado e não uniforme. Outro fator analisado compreendido entre $10 \%$ e $40 \%$. A Figura 3 apresenta as curvas granulométricas do solo e do agregado reciclado.

De acordo com o ensaio de compactação, na energia intermediária, a umidade ótima do agregado reciclado é de $21,75 \%$ e a massa especifica aparente seca de 2,91 g/ $\mathrm{cm}^{3}$. O CBR do agregado reciclado, na umidade ótima, foi de $101,45 \%$, demonstrando que o resíduo possui uma elevada resistência à penetração.

De acordo com a Tabela 1 e a partir dos resultados obtidos nos ensaios, observa-se que o agregado reciclado utilizado no estudo atende aos requisitos especificados pela NBR 15115 (ABNT, 2004).

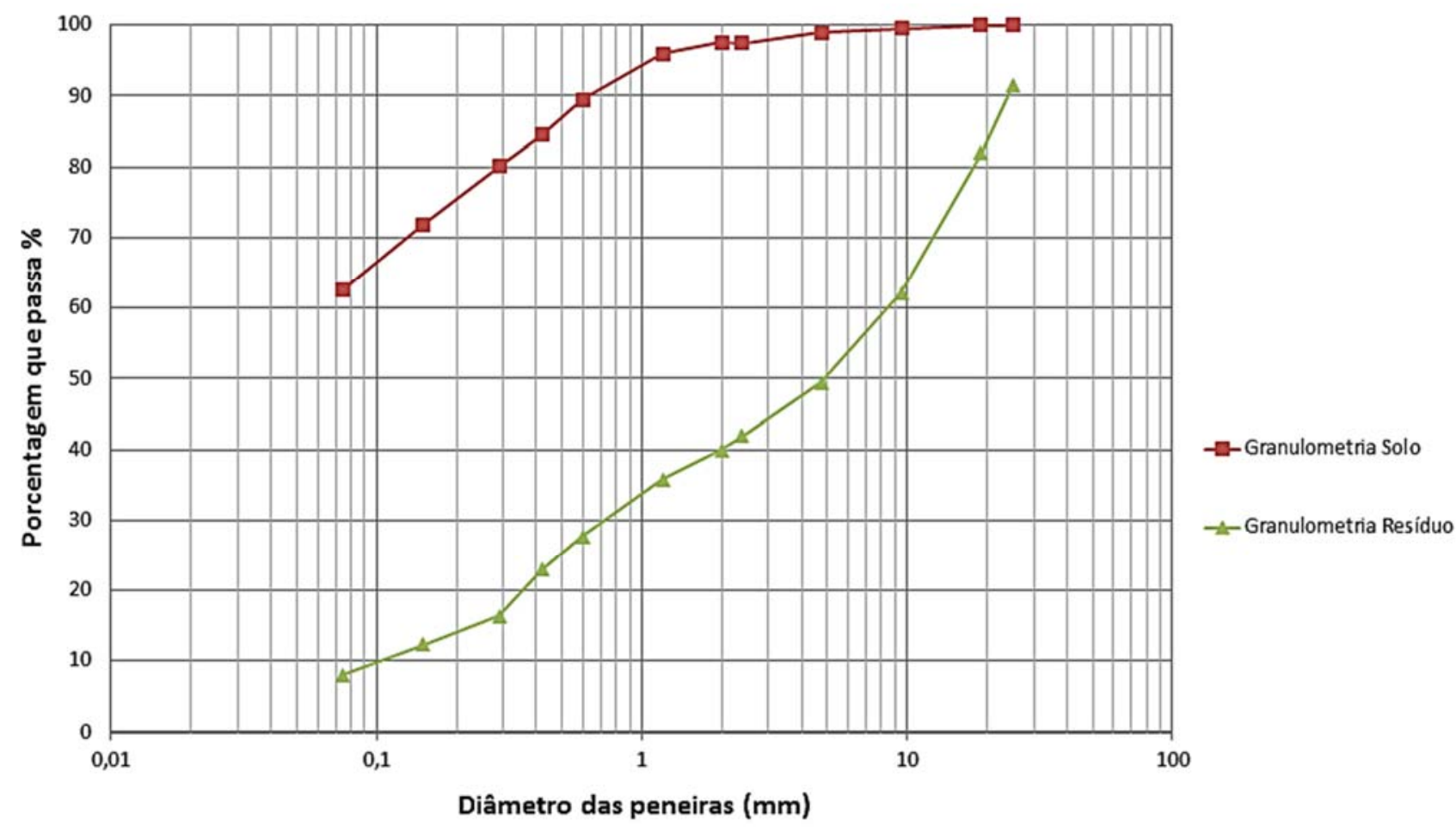

FIGURA 3: Curvas granulométricas do solo e do agregado reciclado. 


\subsection{ESCOLHA DAS PROPORÇÕES DAS MISTURAS DE SOLO-AGREGADO RECICLADO}

Uma das finalidades da pesquisa é buscar o aumento da resistência mecânica do solo da região de Joinville, uma vez que o solo natural da região não apresenta a resistência mínima necessária para a sua utilização na construção de camadas estruturais de pavimentos flexíveis. Para isso, o solo foi estabilizado granulometricamente com agregado reciclado do RCD.

Neste trabalho foi utilizado o método gráfico das áreas balanceadas (Gráfico de Rothfucks) para a dosagem de duas misturas com teores diferentes de materiais: solo e agregado reciclado. Conforme Greco (2007), o método das Áreas Balanceadas ou método Gráfico de Rothfuchs pode ser aplicável a misturas de quantidade quaisquer de materiais. O método consiste em traçar as curvas granulométricas dos materiais disponíveis para a mistura em um gráfico que tenha sido construído de forma que sua diagonal represente a curva média da faixa granulométrica especificada por normas dos Departamentos: Nacional ou Estaduais em Infraestrutura de Transportes.

Após o conhecimento das características físicas do agregado reciclado e do solo é que se procedera à determinação dos teores dos dois materiais nas misturas propostas. O gráfico da Figura 4 mostra as curvas granulométricas do solo e do agregado reciclado. Aplicando o método gráfico das áreas balanceadas determinou-se que a porcentagem de solo é de $44 \%$ e de agregado reciclado de $56 \%$, sendo que esta mistura foi designada de MISTURA 1.

Utilizando-se também o método gráfico das áreas balanceadas foi dosada uma segunda mistura que, em função das curvas granulométricas dos materiais, se enquadrasse o mais próximo possível da faixa granulométrica B do DNIT (Departamento Nacional de Infraestrutura Terrestre). Pela Figura 5 verifica-se que a porcentagem de agregado reciclado e de solo são, respectivamente, $83 \%$ e $17 \%$. Esta mistura foi designada de MISTURA 2.

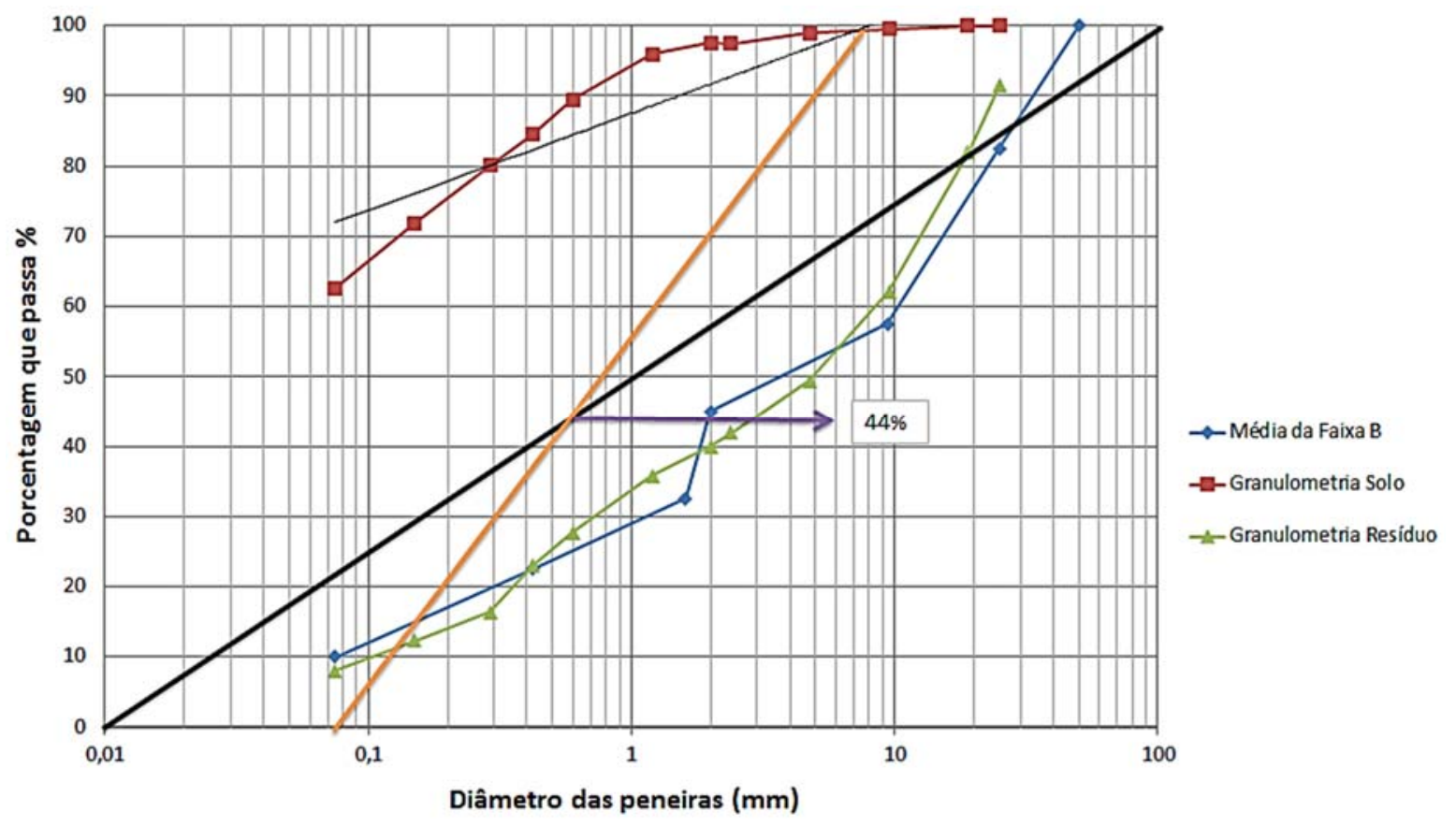

FIGURA 4: Gráfico de dosagem da MISTURA 1. 


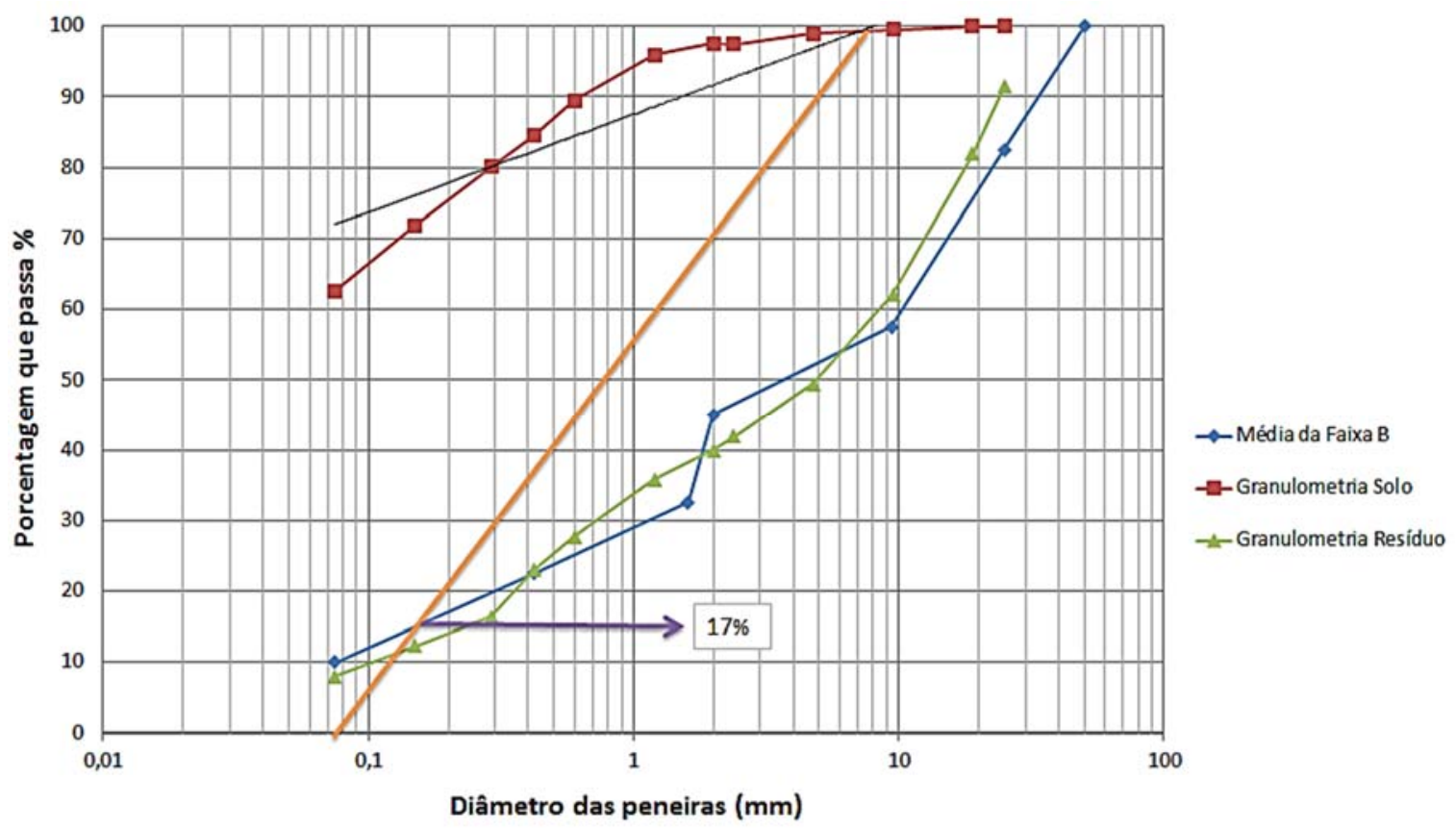

FIGURA 5: Gráfico de dosagem da MISTURA 2.

\subsection{AVALIAÇÃO DA RESISTÊNCIA MECÂNICA DAS MISTURAS}

Após definidas as proporções das duas misturas determinadas, foram conduzidos os ensaios de compactação para a determinação dos respectivos valores de massa específica seca máxima e umidade ótima. Esses ensaios foram realizados de acordo com o descrito na norma NBR 7182 (ABNT, 1984). A energia de compactação escolhida foi a intermediária, do ensaio de Proctor.

A avaliação da resistência mecânica das misturas foi realizada pelo índice de Suporte Califórnia (CBR). O ensaio de CBR foi realizado conforme o especificado pela norma NBR 9895 (ABNT, 1987).

\subsubsection{Mistura 1 ( $44 \%$ solo e $56 \%$ agregado reciclado)}

Do ensaio de compactação, na energia intermediária, obteve- se que a massa específica aparente seca da MISTURA 1 é igual a $1,69 \mathrm{~g} / \mathrm{cm}^{3} \mathrm{e}$ a porcentagem de umidade ótima é de $20,63 \%$. A Figura 6 apresenta as curvas de CBR e expansão da MISTURA 1.

Aplicando a umidade ótima de $20,63 \%$ no gráfico representado na Figura 5, obtém-se o valor de 32,37\% para o CBR da MISTURA 1 . O valor da expansão ótima é de $-0,02 \%$, ocasionando retração.

A MISTURA 1 apresentou um valor de CBR menor que o apresentado pelo agregado reciclado puro. Tal fato já era esperado, visto que a mistura apresenta $44 \%$ de solo em sua composição, o qual apresenta um valor de CBR muito baixo.

\subsubsection{Mistura 2 ( $17 \%$ solo e $83 \%$ agregado reciclado)}

Do ensaio de compactação, na energia intermediária, obteve- se que a massa específica aparente seca da MISTURA 2 é igual a $1,70 \mathrm{~g} / \mathrm{cm}^{3} \mathrm{e}$ a porcentagem de umidade ótima igual a 19,18\%.

A Figura 7 apresenta as curvas de CBR e expansão da mistura 2.0 valor de CBR da MISTURA 2, na umidade ótima, é de $45,65 \%$ e o valor de expansão igual a $0,06 \%$. Como já era esperado a MISTURA 2 apresentou um melhor desempenho quanto à resistência a penetração, justamente por apresentar uma maior porcentagem de agregado reciclado na composição da mistura. 


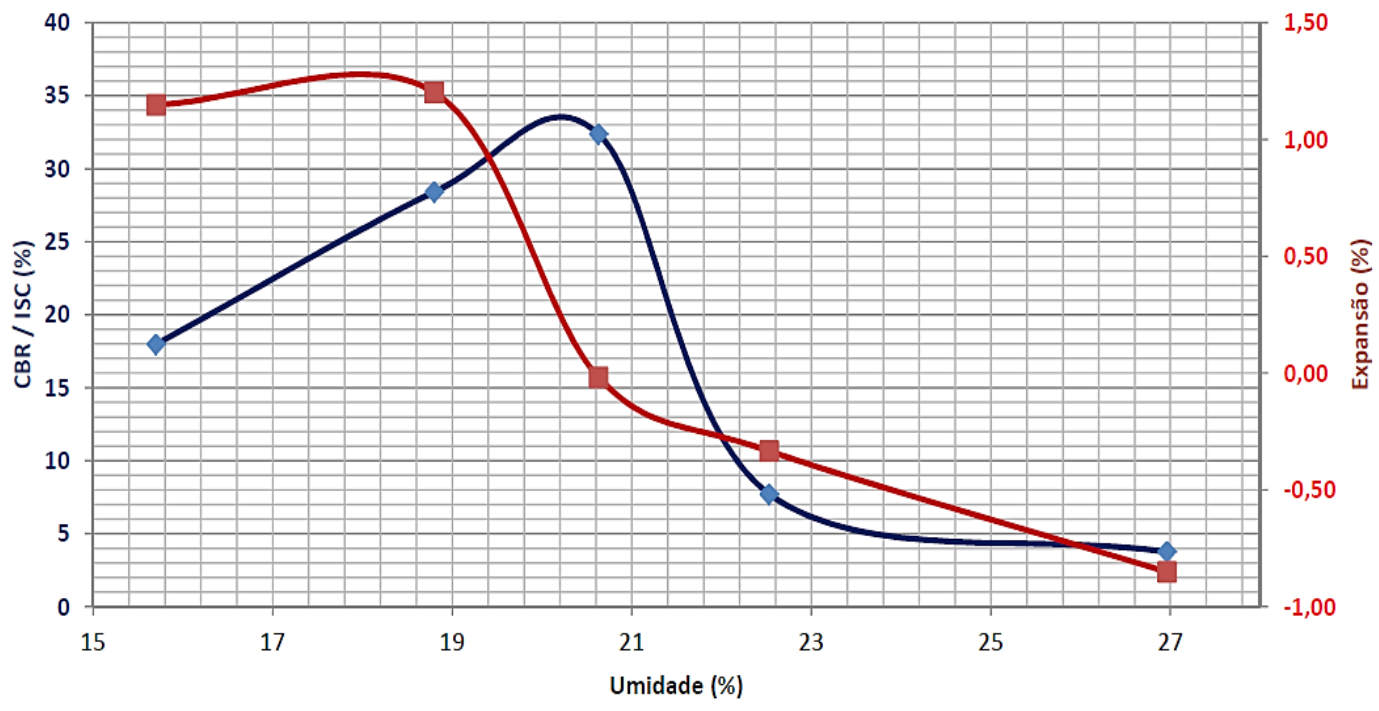

FIGURA 6: Curvas de CBR e expansão da MISTURA 1.

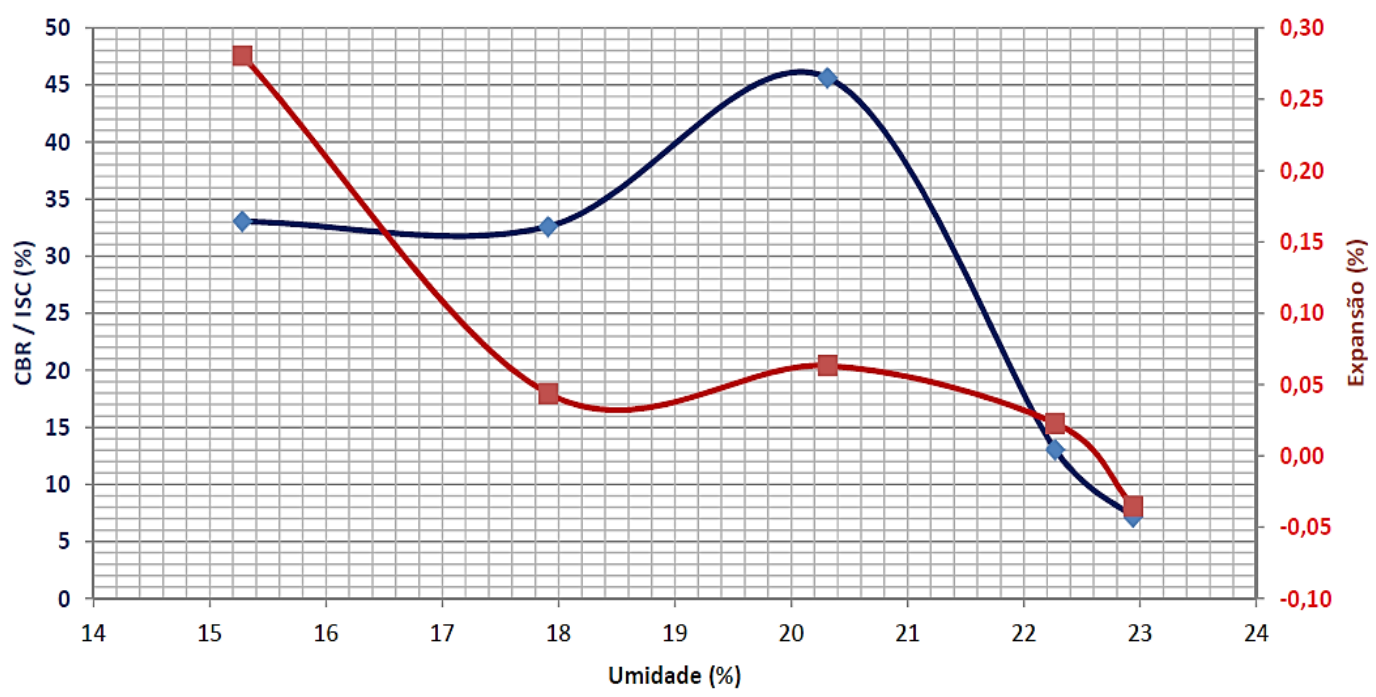

FIGURA 7: Curvas de CBR e expansão da MISTURA 2.

\subsection{DIMENSIONAMENTO DA ESTRUTURA DE PAVIMENTO}

\subsubsection{Cálculo do número do eixo padrão (N)}

No dimensionamento, para efeito de projeto, o tráfego que transitará sobre determinado pavimento ao longo de sua vida útil de serviço é convertido em um número de operações/solicitações de um eixo rodoviário padrão. Este número de solicitações é conhecido como número " $N$ ". O número " $N$ " pode ser calculado pela Equação (1).

$$
\mathrm{N}=\mathrm{Vt} \times \mathrm{Fv} \times \mathrm{Fr}
$$

Eq. [1]

Onde:

$\mathbf{V t}=$ volume total de veículos num determinado sentido para o período $(P)$;

Fv (fator de veículo) = converte todos os tipos de veículos em eixos padrões;

$\mathbf{F r}=$ fator climático regional relacionado ao regime de chuvas de determinado local.

A Tabela 2 apresenta os valores dos parâmetros usados para a determinação do número $\mathrm{N}$ a ser considerado no dimensionamento, pelo método empírico, da estrutura de pavimento 
proposta neste trabalho. Deve-se ressaltar que o valor do volume médio diário de tráfego teve como fonte os dados disponibilizados pelo Instituto de Pesquisa e Planejamento Urbano para o Desenvolvimento Sustentável de Joinville (IPPUJ), para o ano de 2008. Para a determinação dos valores de volumes médios de chuva utilizou-se dados da estação meteorológica da Universidade de Joinville, para o ano de 2010. A taxa de crescimento anual teve como fonte dados do Portal ODM. Aplicando os valores apresentado na Tabela 2 na Equação (1) chega-se que o número $\mathrm{N}$ para a estrutura de pavimento proposta é de $1,68 \times 10^{7}$, que pode ser considerado um valor característico de uma via urbana de tráfego intenso.

\subsection{ANÁLISES DE CUSTO}

A análise de custos da estrutura de pavimento proposta neste trabalho tem como finalidade avaliar a vantagem da utilização do agregado reciclado na construção de camadas de vias urbanas pavimentadas. Desse modo, fez-se um estudo comparativo entre o custo de execução de 1 $\mathrm{km}$ de uma via urbana pavimentada usual para a cidade de Joinville-SC, com a estrutura de pavimento aqui dimensionada.

Para efetuar a análise dos custos foi utilizada uma planilha de composição de custos cedida pela Secretária de Infraestrutura Urbana de Joinville-SC (SEINFRA). A planilha é referente à composição de custos de uma via urbana pavimentada com camada de base executada com brita graduada e a camada de sub-base executada com macadame seco, com plataforma de $8 \mathrm{~m}$. Cabe ressaltar que para a composição dos custos considerou-se os preços de mercado do metro cúbico da brita graduada, do macadame seco e do agregado reciclado puro eram, respectivamente, $\mathrm{R} \$$ $43,00, R \$ 35,50$ e $R \$ 23,00$. Se o agregado reciclado for misturado com solo na proporção mais econômica (menor quantidade de agregado reciclado), que no caso desta pesquisa refere-se à MISTURA 1 (56\% resíduo e 44\% solo), o valor do metro cúbico do material é de $\mathrm{R} \$ 17,00$.

TABELA 2: Parâmetros utilizados para a determinação do número N.

Cálculo do número de eixos padrão

\begin{tabular}{c|c}
\hline Volume médio diário - 2012 [Vm] & 732 \\
\hline Período de projeto [P] & 10 \\
\hline Taxa de crescimento anual [t] & 0,0183 \\
\hline Fator - Tráfego gerado e desviado [k] & 1 \\
\hline Volume médio diário [Vm] & 799 \\
\hline Volume total de tráfego [Vt] & $2,9 \times 10^{6}$ \\
\hline Fator de eixo [FE] & 2,07 \\
\hline Fator de carga [FC] & 1,70 \\
\hline Meses - altura média de chuva inferior $800 \mathrm{~mm}$ & 0 \\
\hline Meses - altura média de chuva entre 800 e $1500 \mathrm{~mm}$ & 5 \\
\hline Meses - altura média de chuva superior $1500 \mathrm{~mm}$ & 7 \\
\hline Fator climático regional [FR] & 1,63 \\
\hline FONTE: IPPUJ (2008).
\end{tabular}




\section{APRESENTAÇÃO DOS RESULTADOS}

De acordo com os resultados obtidos na caracterização física do agregado reciclado, observa-se que o mesmo atende aos requisitos especificados pela NBR 15115 (ABNT, 2004). O CBR do agregado reciclado, na umidade ótima, foi de $101,45 \%$, demonstrando que o material possui uma elevada resistência à penetração.

Já quanto ao solo pode-se observar que o material não se mostrou adequado ao uso em pavimentação, segundo as normas do DNIT, uma vez que seus limites de consistência são muito elevados e o valor de CBR, cujo valor é de $9,87 \%$, é inferior ao mínimo necessário para possa ser utilizado na área rodoviária. Entretanto, após a sua estabilização com o agregado reciclado o valor do CBR aumentou para $32,37 \%$ e $45,65 \%$ considerando, respectivamente, as MISTURAS 1 e 2. Tal incremento possibilita o uso do material como sub-base de pavimentos de elevado volume de tráfego.

Conforme o manual de pavimentação do DNIT (Departamento Nacional de Infraestrutura Terrestre) o material para ser usado na camada de subleito deve apresentar $\mathrm{CBR} \geq 2$ e expansão $\leq 2 \%$. $O$ dimensionamento pelo método empírico do DNIT foi realizado com base no CBR do subleito de valor igual ao do solo natural ensaiado nesta pesquisa, cujo valor é de $9,37 \%$. Este valor faz dispensar a camada de reforço de subleito.

Para a camada de sub-base o mesmo manual determina que o material apresente $\mathrm{CBR} \geq$ $20 \%$ e expansão $\leq 1 \%$. Atendendo a esta determinação pode-se utilizar qualquer uma das duas misturas ensaiadas nesta pesquisa. A MISTURA 1 apresentou valor de CBR igual a 32,37\% e expansão igual a 0,02\%. Já a MISTURA 2 apresentou valor de CBR igual a 45,65\% e expansão igual a $0,06 \%$.
Já para a camada de base há a exigência que o material constituinte deva apresentar $\mathrm{CBR} \geq$ $80 \%$ para $\mathrm{N} \geq 5 \times 10^{6}$ e expansão $\leq 2 \%$. Como nenhuma das duas misturas apresentou valores de CBR condizentes com o requerido foi estipulado que na camada de base usar-se-ia o agregado reciclado puro, cujo CBR apresentou um valor igual a $101,45 \%$.

Para a camada de revestimento foi adotada a espessura de $10 \mathrm{~cm}$ de concreto betuminoso usinado a quente ( $C B \cup Q$ ), que é a espessura de revestimento mínima para um valor de $\mathrm{N}$ compreendido no seguinte intervalo: $10^{7}<\mathrm{N} \leq$ $5 \times 10^{7}$.

De posse dos dados mencionados, utilizou-se o ábaco do DNIT para a determinação da espessura total do pavimento. $O$ pavimento projetado apresentou espessura total de $48 \mathrm{~cm}$ considerando as camadas de sub-base, base e revestimento.

Uma vez determinada a espessura total do pavimento, em termos de material granular, e fixada a espessura do revestimento, procedeu-se ao dimensionamento das espessuras das demais camadas, ou seja, da base e sub-base, levando em conta os materiais disponíveis para cada uma delas, seus coeficientes de equivalência estrutural e suas capacidades de suporte, traduzidas pelos respectivos valores de CBR. Para efeito de dimensionamento o valor CBR para sub-base foi limitado a $20 \%$ e foi considerado o coeficiente de equivalência estrutural (K) para a camada de revestimento igual a 2,0 e para as camadas granulares de base (agregado reciclado) e sub-base (misturas 1 e 2) um valor igual a 1,00.

A Tabela 3 apresenta as espessuras das camadas projetadas para uma via urbana de tráfego pesado da cidade de Joinville-SC.

TABELA 3: Espessuras das camadas projetadas.

Espessura das camadas [cm]

\begin{tabular}{c|c}
\hline Revestimento - CBUQ & 10 \\
\hline Base - RCD & 14 \\
\hline Sub-base - Mistura (Solo-RCD) & 13 \\
\hline
\end{tabular}


A partir disso, foi feita a análise do custo de construção da estrutura de pavimento dimensionada. A Figura 8 representa um gráfico comparativo dos custos de construção de $1 \mathrm{~km}$ das duas vias pavimentadas com materiais distintos de base e sub-base. Pela planilha de composição de custos cedida pelo SEINFRA, a construção de uma estrutura de pavimento usando a brita graduada como camada de base e o macadame a seco como camada de sub-base apresentou um custo de $\mathrm{R} \$$ 802.222,93.

A substituição da base de brita graduada por agregado reciclado puro, bem como a substituição da sub-base de macadame seco pela mistura de solo-agregado reciclado geraria uma redução de custos de $8,8 \%$, já que o custo de construção calculado para essa estrutura foi de R\$ 731. 595, 43. Essa análise é válida considerando os custos iguais para a construção do revestimento e da regularização de subleito para ambas as situações.

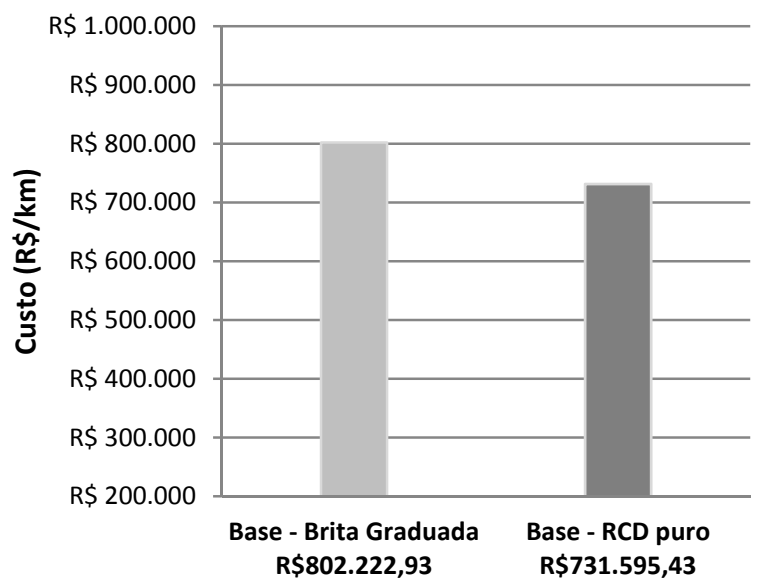

FIGURA 8: Comparação dos custos de construção dos pavimentos analisados.

\section{CONSIDERAÇÕES FINAIS}

Foi realizado o dimensionamento de uma estrutura de pavimento pelo método empírico. Considerando os valores de CBR dos materiais estudados concluiu-se que o solo poderia ser utilizado somente como subleito e que tanto a MISTURA 1 quanto a MISTURA 2 poderiam ser utilizadas como camada de sub-base. Já o agregado reciclado puro, devido à elevada resistência à penetração, poderia ser utilizado como camada de base de pavimento. Desse modo, o dimensionamento estabeleceu que a camada de sub-base fosse executada com $44 \%$ de solo e $56 \%$ de resíduo (MISTURA 1) com uma espessura igual a $13 \mathrm{~cm}$ e que a camada de base fosse executada com agregado reciclado puro com uma espessura de $14 \mathrm{~cm}$.

Fez-se uma análise de custos de execução de $1 \mathrm{~km}$ de uma via urbana executada a partir da estrutura de pavimento proposta no trabalho com uma estrutura de pavimento implantada usualmente na construção de vias urbanas da cidade de Joinville-SC. A partir dos resultados da análise constatou-se que a estrutura de pavimento proposta geraria uma redução de $8,8 \%$ nos custos de construção.

Os resultados alcançados no trabalho incentivam o emprego do agregado reciclado na construção de camadas estruturais de pavimentos. O uso do agregado reciclado pode ser uma alternativa econômica e tecnicamente viável para a área rodoviária, pois o dimensionamento mostrou que o agregado reciclado pode ser utilizado para compor as camadas nobres de um pavimento. Não se deve deixar de mencionar que a utilização dos resíduos de construções e demolições, em obras de engenharia, contribui para $\mathrm{o}$ aumento de construções sustentáveis no Brasil, algo que tem se tornado cada vez mais importante.

\section{REFERÊNCIAS BIBLIOGRÁFICAS}

ASSOCIAÇÃO BRASILEIRA DE NORMAS TÉCNICAS, NBR 15115 Agregados reciclados de resíduos sólidos da construção civil Execução de camadas de pavimentação - Rio de Janeiro, 2004. NBR 7181: Solo - Análise Granulométrica - Rio de Janeiro, 1984a.

NBR 7182: Solo - Ensaio de compactação, Rio de Janeiro, 1984.

. NBR 6459: Solo - Determinação do Limite de Liquidez. Rio de Janeiro, 1984c.

NBR 7180: Solo - Determinação do Limite de Plasticidade. Rio de Janeiro, 1984d. 
NBR 9895: Solo - Índice de Suporte Califórnia. Rio de Janeiro, 1987.

CARNEIRO, A. P.; Burgos, P. C.; Alberte, E. P. V. (2001) Uso do agregado reciclado em camadas de base e sub-base de pavimentos.

CONFEDERAÇÃO NACIONAL DO TRANSPORTE - CNT (2012). Pesquisa CNT de Rodovias 2013 - Relatório Gerencial. Brasília: CNT: Sest: Senat.

DEPARTAMENTO NACIONAL DE ESTRADAS DE RODAGEM, PRO 120/97: Coleta de amostras de agregados. Rio de Janeiro, 1997.

DEPARTAMENTO NACIONAL DE INFRAESTRUTURA TERRESTRE. Manual de pavimentação. $3^{\circ}$ edição. Rio de Janeiro, 2005.

GRECO, J. A. Construção de Estradas e Vias Urbanas: estabilização de materiais, 2007. Notas de aula. Disponível <http://etg.ufmg.br/ jisela/pagina/Projeto\%20de\%20mistura s.pdf>. Acesso em: 21 out. 2013.

HORTEGAL, M. V.; FERREIRA, T. C.; SANT'ANA, W. C. Utilização de Agregados Resíduos Sólidos da Construção Civil para Pavimentação em São Luís - MA. Pesquisa em Foco, São Luís, 2009. v. 17, n.2, p. 60-74.

LEITE, F. C. (2007) Comportamento mecânico de agregado reciclado de resíduo sólido da construção civil em camadas de base e sub-base de pavimentos. Dissertação (Mestrado) Escola Politécnica da Universidade de São Paulo. Universidade de São Paulo, São Paulo/SP. 185 p.

MARINHO, J. L. A.; SILVA, J. D. da. Gerenciamento dos Resíduos da Construção e Demolição: Diretrizes para o Crescimento Sustentável da Construção Civil na Região Metropolitana do Cariri Cearense. In: E-TECH: Tecnologias para competitividade industrial, 2012, Florianópolis, v. 5, n. 1, p. 102-119.

MELO, A. V. S.; et al. Fatores críticos para a produção de agregado reciclado em usinas de reciclagem de RCC da região nordeste do Brasil. Ambiente Construído. Porto Alegre, jul./set. 2013. v. 13, n. 3, p. 99-115.

MOTTA, R. S. (2005). Estudo laboratorial de agregado reciclado de resíduo sólido da construção civil para aplicação em pavimentação de baixo volume de tráfego. Dissertação (Mestrado) - Escola Politécnica, Universidade de São Paulo, São Paulo/SP. 134 p.

OLIVEIRA, M. E. D; et al. Diagnóstico da geração e da composição dos RCD de Fortaleza/CE. Engenharia Sanitária e Ambiental. jul./set. 2011. v. 16 n. 3, p. 219-224.

SILVA, B. T. A.; et al. Avaliação da Energia de Compactação no Desempenho de Mistura Produzida a Partir de Agregados Reciclados para Emprego em Camadas Granulares dos Pavimentos. In: XV Congresso Panamericano de Engenharia de Trânsito e Transporte, 2008, Cartagena de Índias. Anais do VX PANAM, 2008.

TRICHÊS, G.; KRYCKYJ, P.R. Aproveitamento de entulho da construção civil na pavimentação urbana. In: Congresso Brasileiro de Geotecnia Ambiental, 4, São José dos Campos, 1999. Anais. São Paulo: ABMS, 1999, p. 259-265. 